\title{
USO E OCUPAÇÃO DO SOLO URBANO - JARDIM DAS ROSAS - PRESIDENTE PRUDENTE/SP
}

Bruno Oliveira Lopes, Daniele Bosísio, Flórian Gonçalves Alonso Merique, Gabriel Morais Bianchini, Thiago Yugo Nagai Matsutane, Yeda Ruiz Maria

Universidade do Oeste Paulista - UNOESTE, Curso de Arquitetura e Urbanismo, Presidente Prudente, SP. E-mail: yeda rm@hotmail.com

\section{RESUMO}

O plano diretor determina para onde a cidade deve crescer e se desenvolver, estabelecendo também os critérios para o zoneamento urbano com a consequente delimitação das áreas industriais, comerciais e residenciais, estabelecendo assim o uso e ocupação do solo. O uso do solo urbano deve ser definido de acordo com a atividade predominante de seus equipamentos, de forma que tais usos preencham todo o espaço urbano em diferentes proporções de áreas, sendo que estas funções variam no tempo e no espaço e de conformidade com a função da cidade. 0 presente artigo tem como objetivo apresentar e analisar o uso e ocupação existente no Jardim das Rosas afim de entendê-lo como parte integrante da cidade de Presidente Prudente - SP. Para tanto faz-se necessário levantamento bibliográfico pertinente, análise histórico documental do bairro e levantamento in loco para mapeamento e acervo fotográfico.

Palavras-chave: uso e ocupação do solo urbano; expansão urbana; bairro; Jardim das Rosas; Presidente Prudente - SP.

\section{USING AND OCCUPANCY ON THE SOIL BELOW THE JARDIM DAS ROSAS - PRESIDENTE PRUDENTE/SP}

\begin{abstract}
The Urban Master Plane determines the expansion and development of the city, and also determines the technical features for the urban zoning and delimits the industry, commercial and residencial areas, and establishes the use and occupying of soil. The use of the urban soil must be defined according to the predominant activity of its tools, in a way to fulfill the entire urban space in many different proportions of the areas. Moreover, these functions changes in space and time, and according to the function of the city. This article has as objective to present and analyse the use and occupying prevailing at Jardim das Rosas, to understand as an integrant part of Presidente Prudente -SP. Therefore, it is necessary to make a pertinent biographic research, analyse the historical documentation about the place, and "in loco" researches, to maping, and photographic collection.
\end{abstract}

Keywords: use and occupation of urban soil; urban sprawl; neighborhood; Jardim das Rosas; Presidente Prudente - SP. 


\section{INTRODUÇÃO}

As diretrizes de uso e ocupação do solo urbano são estabelecidas como política de desenvolvimento urbano, sendo esta a finalidade do plano diretor (SIRVINSKAS, 2002). O autor pontua que o plano diretor determina para onde a cidade deve crescer e se desenvolver, estabelecendo também os critérios para o zoneamento urbano com a consequente delimitação das áreas industriais, comerciais e residenciais, estabelecendo assim o uso e ocupação do solo.

Segundo Santos (1987), as leis de zoneamento urbano são utilizadas no Brasil já a algum tempo, sendo essas de responsabilidade do município, colocando cada edifício, grupo e atividade em seu melhor lugar, para que a cidade se torne o mais eficiente possível.

Regulamentando os artigos 182 e 183 da Constituição Federal Brasileira de 1988, o Estatuto da Cidade (Lei Federal no 10.257/2001), estabelece as diretrizes gerais da política de desenvolvimento urbano, definindo as normas gerais visando o pleno desenvolvimento das funções sociais da cidade e da propriedade urbana e fornecendo e regulamentando diversos instrumentos de gestão da política urbana.

Portanto, visto como um efetivo instrumento de planejamento, o plano diretor coordena a aplicação das diretrizes previstas no Estatuto da Cidade para o pleno desenvolvimento da urbes e de suas funções sociais, com foco no bem coletivo, na segurança e no bem-estar dos cidadãos. Deve estabelecer estratégias, diretrizes e metas para o desenvolvimento local, atento a vocações, aptidões, restrições, limites e desejos, naturais e da população; exige visão de futuro, de aonde e como se quer chegar; visão local dentro de um contexto global.

Para Ferrari (1977) o uso do solo urbano deve ser definido de acordo com a atividade predominante de seus equipamentos, de forma que tais usos preencham todo o espaço urbano em diferentes proporções de áreas, sendo que estas funções variam no tempo e no espaço e de conformidade com a função da cidade.

Neste sentido admite-se que o uso do solo constitui o elemento principal dentre os instrumentos operacionais a serem utilizados pelo município. O bairro segundo Limonad (1996), é parte fragmentada e articulada da cidade, se organiza e/ou se ordena urbanisticamente conforme os parâmetros sociais, cultural, e econômico do seu povo e espaço, influenciado diretamente pelo poder público.

O lugar (entende-se aqui o bairro Jardim das Rosas), pode ser considerado uma manifestação espacial da apropriação do espaço e da natureza pelo homem, que é inseparável da transformação da sociedade no tempo e no espaço, enfim pode ser entendido como pontos de concentração de condições gerais (LIMONAD, 1996). 
Para Lefebvre (1975), o bairro não pode ser pensado de forma isolada, pois é parte de um todo urbano (a cidade), sem o qual não poderia existir. Portanto, pode-se afirmar que os bairros surgem a partir da expansão urbana de uma cidade e só podem ser entendidos a partir da história e da evolução de uma determinada cidade.

O presente artigo tem como objetivo apresentar e analisar o uso e ocupação existente no Jardim das Rosas afim de entendê-lo como parte integrante da cidade de Presidente Prudente - SP. Para tanto faz-se necessário levantamento bibliográfico pertinente, análise histórico documental do bairro e levantamento in loco para mapeamento e acervo fotográfico.

\section{UM POUCO DE HISTÓRIA}

Consta no web site oficial do museu municipal de Presidente Prudente - SP que a cidade é fruto do desbravamento da região pelos mineiros, os quais buscavam terras para o plantio do café que foi o principal elemento agrícola durante as décadas de 20 e 30.

A produção cafeeira alavancou o desenvolvimento e crescimento do município segundo o web site oficial, onde foi substituída pelo plantio de algodão devido à crise na exportação do café e, em seguida, se estabeleceu forte na cidade e região a produção bovina e de produtos agrários de forma geral, os quais ainda mantinham a região.

O desenvolvimento era contínuo no setor agrário e também no industrial, onde na década de 40, o município já contava com a presença de inúmeras industrias, sendo previsto seu crescimento populacional constante, afirma o web site oficial.

Consta ainda que com sua crescente expansão o setor de serviços foi ganhando então maior diversidade, em paralelo também foi crescente os serviços em áreas como saúde, educação, religião e do comercio no geral. Em seu processo de expansão territorial, o espaço rural foi sendo absorvido continuamente pela cidade.

Neste contexto Rocha (2005) esclarece que expansão urbana é o fenômeno que ocasionalmente gera o aumento e desenvolvimento do perímetro urbano, ou seja a transformação de áreas, as quais legalmente eram rurais em solos urbanos.

Com o desenvolvimento da cidade de Presidente Prudente - SP novos loteamentos foram sendo criados para atender essa demanda, com isso é iniciada a formação dos bairros que compõem o município, sendo um desses o bairro Jardim das Rosas, foco de estudo deste artigo. 


\section{USO E OCUPAÇÃO DO SOLO - O BAIRRO JARDIM DAS ROSAS}

O uso e ocupação do solo faz parte do conjunto de normas que devem estar presentes no plano diretor, delimitando os usos e atividades que poderão ser desenvolvidos em determinada área da cidade, desenvolvendo suas devidas funções sociais. Desta forma organizando essas áreas e seus elementos da melhor maneira possível para uma melhor eficiência da cidade.

O zoneamento urbano (Lei no 153/2008) de Presidente Prudente - SP é executado de forma a complementar os efeitos positivos e negativos do empreendimento ou atividade, quanto à qualidade de vida da população residente nas áreas e suas proximidades, tentando ser organizada de forma que seja a mais eficiente.

O Bairro Jardim das Rosas (fig. 01) está situado em Zona Residencial (ZR2 - cor amarela), sendo essa uma zona residencial de média densidade populacional, podendo ter ocupação horizontal e vertical de até dois pavimentos, com ocupação máxima de edifícios residenciais de até 70\%, com tamanho mínimo de 250 metros quadrados por lote. É permitido residência unifamiliar, residência multifamiliar, comércio e serviço vicinal e comércio e serviço de bairro e tolerável a existência de comércio e serviço em geral, comércio e serviço específico e Indústria não poluitiva.

Há ainda no entorno do bairro a Zona especial de ensino e pesquisa (onde está localizado a faculdade Estadual Paulista, FCT-Unesp), Zona especial de clubes recreativos (onde está situado o SESC Termas de Presidente Prudente e Zona especial de recreação e lazer, sendo essa a praça dos imigrantes. Também podemos ver no mapa as vias de acesso ao bairro segundo sua hierarquia, sendo elas vias de acesso rápido (roxo) e vias coletoras (vermelho).

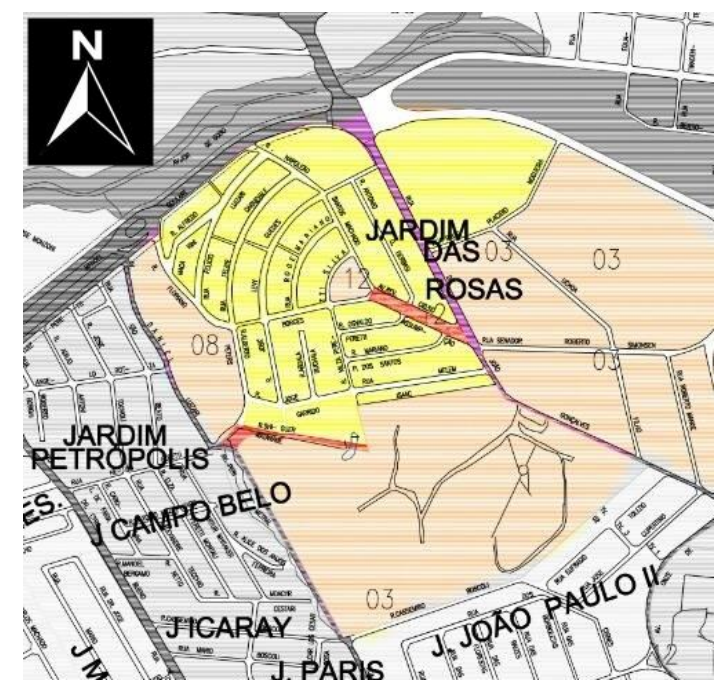

Figura 01. zoneamento urbano - Bairro Jardim das Rosas - sem escala. Fonte: Web site da Prefeitura Municipal de Presidente Prudente - SP 
Entretanto os levantamentos in loco apresentam uma dinâmica um pouco diferente, que nem todos os direcionamentos estabelecidos pelo zoneamento urbano para a ZR2 são seguidos à risca (fig. 02).

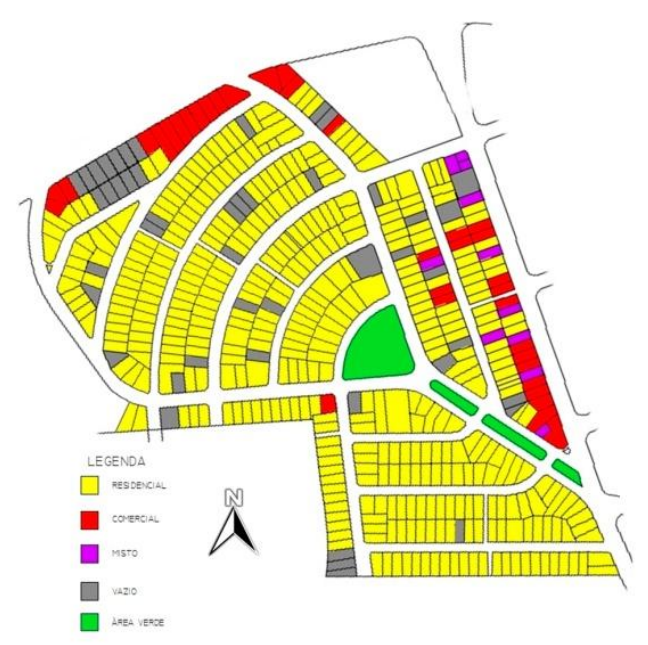

Figura 02. Levantamento uso e ocupação - sem escala

Fonte: autores, 2015.

Constata-se que a maioria dos lotes são usados com função residencial (cor amarelo) de uso unifamiliar e multifamiliares (Ex.: casas geminadas). Há poucos lotes com função única comercial (cor vermelho), ocorre entretanto o uso misto (cor roxo) do lote (Ex.: residência + comercio), os quais se concentram nas proximidades da Av. Manoel Goulart e Rua Dr. José Gonçalves Foz. Podendo concluir que essa formação do bairro se dá através dos interesses encontrados para aquela área, onde devido a existência da faculdade é grande a procurar por residências nas proximidades para maior comodidade. A área comercial também é tendenciada de acordo com os interesses, sendo os comércios localizados em áreas de maior visibilidade, grande movimentação e fluxo de pessoas.

A permeabilidade do solo, gabarito de altura e coeficiente de aproveitamento também são quesitos não seguidos. Muitas vezes sem conhecimento das normas de ocupação do solo, as pessoas não o utilizam da melhor forma possível, segundo os padrões estabelecidos pela lei de zoneamento urbano. Uma vez que o zoneamento foi estabelecido a partir de estudos para adequar a ocupação do solo de forma a proporcionar a maior eficiência e qualidade de vida para os habitantes locais. Não seguindo as normas propostas, pode gerar problemas de desordem urbana, especulação imobiliária, ambientais entre outros. 


\section{CONCLUSÃO}

Conclui-se que o zoneamento de uso e ocupação do solo é sim uma ferramenta de grande importância no processo de expansão da cidade, através dele o solo urbano pode ser separado e classificado de forma organizada para que a cidade se torne eficiente, desde que sua classificação seja feita em cima de análises e estudos feitos sobre o espaço urbano, suas atividades e a população existente.

De certa forma, o poder público através dessa ferramenta tenta controlar o crescimento e desenvolvimento da cidade, que deviam ir de acordo sempre com a melhoria do ambiente para as pessoas que ali vivem. $\mathrm{O}$ que nem sempre é ocasionado, esse fato podendo ocorrer por diversos fatores tais como, falta de estudo e preparo correto da área, falta de interesse e em alguns casos até os próprios habitantes. O zoneamento é determinado por normas, mas esse não podendo prever com total certeza o pensamento e o interesse humano.

No bairro em questão, podemos levar em conta, que com o passar dos anos o bairro foi passando por mudanças constantes, influenciadas por seus entornos, levando a mudar juntamente com ele e com os interesses das pessoas que ali agora estão. Deixando muitas vezes de lado, as normas do uso e ocupação do solo estabelecidos para a área. O bairro que a princípio era de interesse familiar, vêm sofrendo alterações por influência da presença da Unesp, onde é cada vez mais comum o surgimento de moradias voltadas aos estudantes, principalmente nas áreas que estão mais próximas da faculdade, o que antes não era tão intenso. Os comércios também, os quais são localizados nos limites do bairro estão agrupados nas vias de maior fluxo, por interesses comerciais dos donos, sendo poucos os que são voltados para o benefício da própria população ali presente. Nos entornos são encontrados comércios para todo o tipo de prestação de serviços dos moradores, mesmo não sendo eficiente, muitas vezes em relação à acessibilidade dos próprios moradores, com isso o bairro não fica defasado. De acordo com o zoneamento a organização dos espaços dentro do bairro se dariam para uma melhor condição de vida da população local, isso entrando em conflito com os interesses comerciais e de fins capitalistas, onde o crescimento existente no bairro segue os interesses sem respeitar as normas estabelecidas para ele feitas através de estudos urbanos.

\section{REFERENCIAS}

FERRARI, Celson. Curso de planejamento municipal integrado: urbanismo. São Paulo: Pioneira, 1977. 
HISTÓRIA DE PRESIDENTE PRUDENTE. Museu e Arquivo Histórico Prefeito Antônio Sandoval Netto. Disponível em: <http://museu.presidenteprudente.sp.gov.br/historiapp.php> Acesso em: 21 de julho de 2015.

LEFEBVRE, Henri. O direito à cidade. São Paulo. Documentos LTDA. 1969.

LEI 10.257/2001. Estatuto das Cidades. Disponível em: <http://polis.org.br/wpcontent/uploads/estatuto_cidade_compreender.pdfhttp://www.planalto.gov.br/ccivil/LEIS/LEIS_2 001/L10257.htm.> Acesso em: 13 de julho de 2015.

LEI COMPLEMENTAR № 153/2008. Lei de Zoneamento do Uso e Ocupação do Solo, da Área Urbana do Município de Presidente Prudente. Disponível em:

<http://www.presidenteprudente.sp.gov.br/site/Documento.do?cod=612> Acesso em: 25 de julho de 2015.

LIMONAD, ESTER. Os lugares da Urbanização: O caso no interior fluminense. 1996. 247f. Tese de Doutorado (Faculdade de Arquitetura e Urbanismo) - Universidade de São Paulo, São Paulo, 1996.

ROCHA, Aristotelina Pereira Barreto. Expansão urbana de Mossoró (período de 1980 a 2004): geografia dinâmica e reestruturação do território / Aristotelina Pereira Barreto Rocha. - Natal, RN: EDUFRN Editora da UFRN, 2005.

SANTOS, Carlos Nelson F. O Uso do Solo e o Município. Rio de Janeiro: IBAM, 1987.

SIRVINSKAS, Luís Paulo. Manual do Direito Ambiental. Saraiva: São Paulo, 2002. 